\title{
Universal neonatal hearing screening program at a university hospital: an analysis using quality indicators
}

Audrei Thayse Viegel de Avila ${ }^{1}$ https://orcid.org/0000-0002-1322-6426

Adriane Ribeiro Teixeira ${ }^{2}$ https://orcid.org/0000-0003-4242-1666

Luíza Silva Vernier ${ }^{3}$ https://orcid.org/0000-0002-4263-9991

Adriana Laybauer Silveira ${ }^{4}$ https://orcid.org/0000-0003-0713-9016

Hospital de Clínicas de Porto Alegre HCPA, Residência Multiprofissional em Saúde, Porto Alegre, Rio Grande do Sul, Brasil.

Universidade Federal do Rio Grande do Sul - UFRGS, Curso de Fonoaudiologia, Porto Alegre, Rio Grande do Sul, Brasil. Universidade Federal de Ciências da Saúde de Porto Alegre - UFCSPA Departamento de Ciências Médicas, Programa de Pós-graduação (Doutorado) em Medicina e Métodos Diagnósticos, Porto Alegre, Rio Grande do Sul, Brasil.

Hospital de Clínicas de Porto Alegre HCPA, Porto Alegre, Rio Grande do Sul, Brasil.

This study was developed in Multiprofessional Health Residence at the Clinics Hospital of Porto Alegre - HCPA, Porto Alegre, Rio Grande do Sul, Brazil.

Conflict of interests: Nonexistent

\section{(c) (i)}

Received on: June 4, 2021

Accepted on: September 24, 2021

Corresponding address:

Adriana Laybauer Silveira

Hospital de Clínicas de Porto Alegre - HCPA

Rua Ramiro Barcelos, 2350/Zona 19 -

subsolo, Santa Cecília

CEP: 90035-007 - Porto Alegre

Rio Grande do Sul, Brasil

E-mail: alsilveira@hcpa.edu.br

\section{ABSTRACT}

Purpose: to assess the universal neonatal hearing screening program using quality indicators.

Methods: the records of newborns who were submitted to the neonatal hearing screening in 2018 were analyzed, comparing the data with the first five quality indicators established by the national guideline for neonatal hearing screening attention: 1) rate of screening coverage ( $\geq 95 \%) ; 2$ ) age at the screening in months (up to the first month of life); 3 ) rate of referrals for diagnosis (2\% to $4 \%$ ); 4) rate of attendance to diagnostic examination ( $\geq 90 \%$ ); 5 ) age at confirmed diagnosis (up to the third month of life). The data were submitted to quantitative and descriptive statistical analysis.

Results: the rate of coverage, age at screening, and the number of referrals for diagnosis met the indicators established by the national guideline. The rate of attendance to diagnostic examination fell short of the expected, and the age at confirmed diagnosis was verified in $70 \%$ of the cases.

Conclusion: using the quality indicators furnished important data on the effectiveness of the neonatal hearing screening program and identified opportunities to improve the service, which can help identify hearing loss, early.

Keywords: Hearing; Neonatal Screening; Newborn; Quality Control 


\section{INTRODUCTION}

The Universal Neonatal Hearing Screening (UNHS) is an integral part of the health care network for people with a disability and mother and child attention. Federal Law 12.303, passed in 2010, made it mandatory for hospitals and maternities to perform evoked otoacoustic emission examinations for free in neonates born in their premises ${ }^{1}$. The objective of the UNHS programs is to detect hearing loss $(\mathrm{HL})$, early, and once identified, promote timely hearing rehabilitation ${ }^{1,2}$.

The importance of detecting abnormal hearing early lies in the fact that the maturation of the central auditory nervous system up to the brainstem occurs in the first years of life. This period is essential to auditory and language development because that is when most neural connections take place ${ }^{3}$. Hence, identifying $\mathrm{HL}$ early favors communication development', ${ }^{2,4}$.

The UNHS, which is the first phase of a complete hearing health program, must encompass sensitive and quick procedures. It includes test, retest, diagnosis, rehabilitation, and auditory and language monitoring. The transient evoked otoacoustic emissions (EOAE) and the automated brainstem auditory evoked potentials (A-BAEP) are the recommended UNHS procedures $^{2,4}$.

TEOAE is a noninvasive procedure that detects possible hearing changes in newborns (RN) without risk indicators for hearing loss (RIHL). NBs with RIHL, in their turn, are assessed with A-BAEP, which is a noninvasive electrophysiological method that assesses the cochlea, auditory nerve, and brainstem to identify hearing changes greater than or equal to $35 \mathrm{dBHL}^{5}$.

Some national and international documents recommend the procedures for the UNHS. They instruct that such screening must be universal and that the NBs should be preferably assessed on the first days of life or, at the most, the first month of life. Moreover, organized referrals must be made to the other stages of the program. The American Academy of Pediatrics (AAP) and the Joint Committee on Infant Hearing (JCIH) recommend the UNHS be provided universally, with quality indicators to be met by the programs ${ }^{2,4-6}$.

Aiming to verify and monitor the effectiveness of UNHS programs in Brazil, the national guideline for neonatal hearing screening attention (DNATAN, in Portuguese) recommends the following quality indicators: 1) $95 \%$ or more UNHS coverage rate for live NBs, aiming at $100 \%$; 2) age at UNHS, in months (up to the first month of life, or the third month of life [corrected age], at the most, in cases of premature birth or hospitalization); 3) $2 \%$ to $4 \%$ of the NBs referred for diagnosis; 4) at least $90 \%$ attendance to diagnostic examination; 5) age at diagnosis (up to the third month of life); 6) beginning the speech-language-hearing therapy as soon as a diagnosis is reached in $95 \%$ of infants with bilateral $\mathrm{HL}$; 7) hearing aid (HA) fitted within 1 month from diagnosis in 95\% of the infants diagnosed with permanent unilateral or bilateral $\mathrm{HL}^{2}$.

At the hospital where the study was carried out, the UNHS follows the speech-language-hearing service protocol and the existing Brazilian law ${ }^{2}$. Thus, the flow is organized according to the ward where the NB is staying. NBs staying at the obstetrics ward are screened within 24 to 48 hours of life, whereas those staying at the neonatal ward are assessed when they stabilize and/or when they most use ototoxic medications, preferably at hospital discharge. Patients who are not submitted to UNHS during the hospital stay are referred to a follow-up visit to the audiology outpatient center.

The DNATAN instructs the use of databanks to control and record the information on all program stages, which enable the monitoring of the above mentioned quality indicators ${ }^{2}$. The effectiveness of the UHS program, verified with standardized quality indicators, may lead to earlier audiological intervention and, consequently, the child's overall development which justifies this study, which aimed to assess the UNHS program,using quality indicators.

\section{METHODS}

This research was approved by the Research Ethics Committee (REC) of the Clinics Hospital of Porto Alegre (HCPA), Brazil, under protocol number 2019.0277 and Certificate of Presentation for Ethical Appraisal (CAAE) 12679318000005327. Since this is a retrospective study, it was exempted from the informed consent form. To this end, its authors committed themselves to using the surveyed data exclusively for scientific purposes, maintaining their confidentiality.

The sample comprised all UNHS records of live neonates born at the hospital with a request for screening at birth, in the period of the analysis (from January 1,2018 , to December 31,2018 ), totaling 3,486 requests.

The inclusion criteria were as follows: all medical records of live NBs at the hospital, in the period covered by the study, who were submitted to UNHS. The medical records of live NBs with a request for UNHS 
but who died, as well as those with incomplete information on all the variables researched, were excluded.

This is a retrospective, descriptive, cross-sectional, observational study. The research was based on data collected from the hospital's electronic medical records. The surveyed data referred to NBs who stayed at the obstetrics or neonatal ward, or who were referred for UNHS at the outpatient center.

After the research project was approved by the REC, the researchers accessed the data via the hospital's electronic system, identifying the patients based on the requests for UNHS. This request is made automatically when the live NB is included in the system, soon after birth.

A databank was developed in Microsoft Excel ${ }^{\circledR} 2010$ with the information, which encompassed the following variables: date of birth, date of UNHS, place of the procedure, UNHS result (either TEOAE or A-BAEP), date of retest, date of diagnosis, date of a confirmed diagnosis, and the result of the diagnosis.

The data were analyzed with the Statistical Package for the Social Sciences ${ }^{\circledR}$ (SPSS) for Windows ${ }^{\circledR}$, version 20.0. The results are presented with descriptive statistics, as absolute (n) and relative distribution (\%). Continuous variables were presented as median, minimum, and maximum.

The results were compared with the quality indicators established by DNATAN as a reference, namely:

1) UNHS coverage rate for live NBs (95\%);

2) age at UNHS, in months (up to the first month of life or, at the most, the third month of life), considering premature births and long hospital stays;

3) rate of NBs referred for diagnosis (2\% to $4 \%$ );

4) rate of attendance to diagnostic examination $(90 \%)$;

5) age at confirmed diagnosis (up to the third month of life).
DNATAN sixth and seventh indicators, which refer to the time until the speech-language-hearing therapy and until HA fitting, were not addressed in this study analysis because some patients are referred to other public health care institutions for hearing rehabilitation, following the state's regulation system.

\section{RESULTS}

The total study sample comprised 3,486 UNHS requests. In 2,675 (76.7\%) of them, the UNHS was performed at the obstetrics ward; 653 (18.7\%), at the neonatal ward; $158(4.5 \%)$ at the outpatient center. Of the total sample, $3,430(98.3 \%)$ were submitted to UNHS, while $56(1.7 \%)$ were not (Table 1). As for the procedures, 2,581 (75\%) used TEOAE and 849 (25\%), A-BAEP.

In the first UNHS stage (test), the TEOAE recordings found normal results in both ears in 2,196 cases (64\%), abnormal in both ears in 110 (3.2\%), abnormal only in the left ear in 145 (4.2\%), and only in the right ear in 130 (3.8\%). The A-BAEP recordings revealed normal results in both ears in 780 cases (22.7\%), abnormal in both ears in $24(0.69 \%)$, abnormal only in the left ear in 22 $(0.64 \%)$, and only in the right ear in $23(0.67 \%)$.

A total of 441 patients (12.8\%) were referred for the second stage (retest). Of these, 350 (79.4\%) had a normal retest result, 75 (17\%) did not attend it, and 16 (3.6\%) remained with an abnormal result. Also, seven patients did not undergo retest; instead, they were referred directly for diagnosis due to their prolonged hospital stay.

As for the NBs' age at UNHS, $96.2 \%$ were submitted to it within 30 days of life; $3.3 \%$, within 90 days; $0.5 \%$, after 90 days (Table 1). Regarding age at the second UNHS stage (retest), $87.7 \%$ were submitted to it within 30 days of life. 
Table 1. Absolute and relative distribution of the neonatal hearing screening coverage, age at screening, and referrals for diagnosis

\begin{tabular}{lcc}
\hline \multirow{2}{*}{ Variables } & \multicolumn{2}{c}{ Total sample ( $\mathbf{n = 3 , 4 8 6 )}$} \\
\cline { 2 - 3 } NHS coverage & Absolute frequency $(\mathbf{n})$ & Relative frequency (\%) \\
Was submitted to NHS & 3,430 & $98.3 \%$ \\
Was not submitted to NHS & 56 & $1.7 \%$ \\
Age at NHS & 3,301 & $96.2 \%$ \\
Up to 30 days & 113 & $3.3 \%$ \\
Up to 90 days & 13 & $0.5 \%$ \\
$>90$ days & & $0.7 \%$ \\
Referrals for diagnosis & 23 & \\
\end{tabular}

Captions: NHS = neonatal hearing screening; $\mathrm{n}=$ number (absolute value); $\%=$ percentage

The patients referred for diagnosis corresponded to $0.7 \%$ of the total sample. Of this group, $86.9 \%$ attended the diagnostic examination, while $13.1 \%$ did not. The age at confirmed diagnosis was up to 90 days in $70 \%$ of the subjects and more than 90 days in $30 \%$ of them (Table 2). The median time from screening to confirmed diagnosis was 30 days - a minimum of 13 days and a maximum of 252 days (Table 3 ).

Seven cases were diagnosed with unilateral or bilateral $\mathrm{HL}$, which corresponds to $0.2 \%$ of the total patients who underwent UNHS.

Table 2. Absolute and relative distribution of attendance to diagnostic examination, age at confirmed diagnosis, and patients diagnosed with hearing loss

\begin{tabular}{lcc}
\hline Variables & \multicolumn{2}{c}{ Total sample ( $\mathbf{n = 2 3})$} \\
\cline { 2 - 3 } & Absolute frequency $(\mathbf{n})$ & Relative frequency (\%) \\
\hline Attendance to diagnostic examination & 20 & $86.9 \%$ \\
Attended & 3 & $13.1 \%$ \\
Did not attend & & \\
Age at confirmed diagnosis & 14 & $70.0 \%$ \\
Up to 90 days & 6 & $30.0 \%$ \\
$>90$ days & & $35.0 \%$ \\
Patients diagnosed with HL & 7 & \\
\end{tabular}

Captions: $\mathrm{HL}=$ hearing loss; $\mathrm{n}=$ number (absolute value); $\%$ = percentage 
Table 3. Absolute distribution of the total days until the diagnosis and median number of days until the diagnosis

\begin{tabular}{ccc}
\hline Variables & Total days until the diagnosis $(\mathbf{n})$ & Median days until the diagnosis $(\mathbf{n})$ \\
\hline Patients & 137 & 30* \\
1 & 17 \\
3 & 220 \\
4 & 30 \\
5 & 13 \\
6 & 14 \\
7 & 55 \\
8 & 10 \\
9 & 14 \\
11 & 13 \\
12 & 108 \\
13 & 30 \\
14 & 31 \\
15 & 26 \\
16 & 48 \\
17 & 103 \\
18 & 252 \\
20 & 30 \\
21 & 120 \\
22 & 103 \\
23 &
\end{tabular}

Captions: $\mathrm{n}=$ number (absolute value); * median days until the diagnosis of all patients in the sample

\section{DISCUSSION}

The literature shows that UNHS, including TEOAE and A-BAEP, is essential to detecting HL early and then referring the patients to habilitation/rehabilitation. Early diagnoses enable timely auditory stimulation, aiming to decrease the auditory deprivation time and give the child the opportunity to develop their language and communication, minimizing future social, academic, and occupational deficits ${ }^{2,4,5}$. For the UNHS program to be effective, they need to meet the quality indicators established by the Ministry of Health².

In this study, the UNHS coverage rate was $98.3 \%$, which meets the expected by the indicators (a minimum of $95 \%$ ). National and international studies that likewise assessed UNHS program coverage found similar coverage rates ${ }^{7-10}$. Some programs in Brazil had a coverage lower than $95 \%$; however, all these performed the UNHS at an outpatient setting - i.e., after hospital discharge ${ }^{11-14}$.

The non-adherence to the UNHS - i.e., non-attendance to the test, retest, or diagnostic examination is one of the main barriers to successful screening programs ${ }^{15}$. Socioeconomic and cultural factors may explain the non-adherence on the part of the families.
Performing the UNHS before hospital discharge helps increase the screening coverage ${ }^{16,17}$.

Regarding their age at UNHS, $96.2 \%$ were submitted to it within the first 30 days of life, as expected in the quality indicators ${ }^{2}$, while $3.8 \%$ were submitted to UNHS after the first month. It may be performed after the first month of life due to factors such as prematurity, comorbidities, patient instability, and ototoxic medications taken during the hospital stay. Nevertheless, screening them within the first month of life is justified by the importance of reaching a diagnosis as early as possible $e^{10,18,19}$.

Of the total NBs, 23 were referred for diagnosis. This corresponds to $0.7 \%$ of those assessed - i.e., below the rate expected in the quality indicators ${ }^{2}$, which require that $2 \%$ to $4 \%$ of the NBs be assessed. Other studies that made the same assessment respectively found $0.25 \%, 0.81 \%, 1 \%, 2.1 \%, 2.4 \%^{10,14,20,21}$. Improvements in the screening process with A-BAEP may have helped decrease the number of NBs referred for diagnosis, as studies with higher numbers of NBs referred for diagnosis used only TEOAE as the assessment method. Some population characteristics, such as a 
higher incidence of RIHL, may also explain such higher rates $^{10,14}$.

Of the NBs referred for diagnosis, $86.9 \%$ attended it, which is below the expected in the indicators $(90 \%)^{15}$. Other pieces of research found diagnostic attendance rates below $70 \%{ }^{22-24}$. Psychosocial and socioeconomic factors - e.g., distance from their home to the place of the diagnostic examination, transportation difficulties, the parents' work schedule, changing address and phone numbers - raise barriers to continuous follow-up, making it necessary to actively seek these patients ${ }^{23,24}$.

The present study showed a $70 \%$ rate of infants who had their diagnosis confirmed by the third month of life. In the context of this research, this result may be explained by the patients' long hospital stay (it is a reference hospital for NBs with a severe health condition) - in which case the screening took place after the 30 days of life - and the intense demand in the services combined with a shortage of personnel available to carry out all the phases of audiological follow-up. Confirming the diagnosis by the third month is important to the child's development, as it allows them to undergo the rehabilitation process throughout the first year of life. This period is when the maturation process of the central auditory nervous system accelerates because of the increasing number of neural connections, furnishing them great brain plasticity. When the auditory pathways pick up acoustic signals early in life, there is a direct effect on the child's language and speech development and successful hearing habilitation ${ }^{3,5}$.

Seven out of 20 NBs were identified with some type of HL (one to two per 1,000 live births), corroborating the findings of another study ${ }^{9}$. Childhood $\mathrm{HL}$ prevalence rates can reach three per 1,000 live births, which is a high incidence when compared with other diseases detectable with neonatal screenings - such as the genetic and metabolic ones detected with the heel prick, whose results indicate one patient with one of these diseases per 10,000 live births ${ }^{25}$. Early HL identification influences both the HA fitting process and the referral for a cochlear implant. However, this requires enough personnel available for timely audiological follow-up ${ }^{18,26}$.

The quality indicators help the services recognize whether the objectives have been metor fallen short of expectations, thus cooperating with the organization of quality and efficient services. To this end, though, it is necessary that the data collection instruments that monitor the quality indicators be rethought and improved. The data obtained in combination with indicators reveal gaps and help plan improvements in the service. Electronic tools are essential in this process because they make it easier to obtain data and results ${ }^{27}$.

Implemented UNHS programs have reduced the mean age of $\mathrm{HL}$ identification. Assessing screening programs with quality indicators can optimize the processes and provide improvement perspectives. Nonetheless, to meet quality standards, the management and monitoring systems must be improved, along with raising public awareness of the importance of the UNHS ${ }^{24}$. As UNHS programs are monitored, knowledge will increase on congenital $\mathrm{HL}$ epidemiology in Brazil, contributing to timely audiological intervention and helping propose adequate public policies for early childhood ${ }^{4,28}$.

A limitation of this study was the impossibility to assess the whole UNHS program because hearing rehabilitation, in some cases, took place in other institutions or municipalities, following regulations of the state and municipal departments of health.

\section{CONCLUSION}

The assessment of the UNHS program with the quality indicators revealed that the coverage rate for live births, age at UNHS in months, and the number of referrals for diagnosis met the standards established by DNATAN. The rate of attendance to diagnostic examination (86.9\%) was below the indicated in the guideline. The age expected for confirmed diagnosis (within 3 months of life) was verified in $70 \%$ of the cases. The median time from the end of screening to the diagnosis was 30 days.

\section{REFERENCES}

1. Brasil. Lei n. 12.303, de 2 de agosto de 2010. Dispõe sobre a obrigatoriedade de realização do exame denominado emissões otoacústicas evocadas. Diário Oficial da União. De agosto de 2010. Available at: http://www.planalto.gov.br/ ccivil_03/_Ato2007-2010/2010/Lei/L12303.htm 
2. BRASIL. Ministério da Saúde. Diretrizes de Atenção da Triagem Auditiva Neonatal. Secretaria de Atenção à Saúde. Secretaria de Atenção à Saúde. Departamento de Ações Programáticas Estratégicas e Departamento de Atenção Especializada. Brasília: Ministério da Saúde, 2012. Available at: https://bvsms.saude.gov.br/bvs/ publicacoes/diretrizes_atencao_triagem_auditiva_ neonatal.pdf

3. Cardon G, Campbell J, Sharma A. Plasticity in the developing auditory cortex: evidence from children with sensorineural hearing loss and auditory neuropathy spectrum disorder. J Am AcadAudiol. 2012;23(6):396-410.

4. Joint Committee on Infant Hearing. Joint Committee on Infant Hearing 2019 Position Statement. Principles and guidelines for early hearing detection and intervention programs. JEHDI. 2019;4(2):1-44.

5. Alvarenga KF. Avaliação audiológica em bebês: 0 a 1 ano de idade. In: Bevilacqua MC, Martinez MAN, Balen AS, Pupo AC, Reis ACMB, Frota S, editors. Tratado de Audiologia. 1aed. São Paulo: Santos; 2012.p.517-32.

6. Lewis DR, Marone SAM, Mendes BCA, Cruz OLM, Nóbrega M. Comitê multiprofissional em saúde auditiva. Braz J Otorhinolaryngol. 2010;76(1):121-8.

7. Kemp AAT, Delecrode CR, da Silva GC, Martins F, Frizzo ACF, Cardoso ACV. Neonatal hearing screening in a low-risk maternity in São Paulo state. Braz J Otorhinolaryngol. 2015;81(5):505-13.

8. Caluraud S, Marcolla-Bouchetemblé A, Barros A, Moreau-Lenoir F, Sevin E, Rerolle $S$ et al. Newborn hearing screening: analysis and outcomes after 100,000 births in Upper-Normandy French region. Int J Pediatrotorhinolaryngol. 2015;79(6):829-33.

9. Wood SA, Sutton JG, Davis AC. Performance and characteristics of the Newborn Hearing Screening Programme in England: the first seven years. Int $\mathrm{J}$ of Audiol. 2015;54(6):353-8.

10. Vos B, Lagasse R, Levêque A. Main outcomes of a newborn hearing screening program in Belgium over six years. Int $\mathrm{J}$ Pediatrotorhinolaryngol. 2014;78(9):1496-502.

11. Lima PT, Goldbach MG, Monteiro MC, Ribeiro MG. A triagem auditiva neonatal na rede municipal do Rio de Janeiro, Brasil. Ciênc Saúde Colet. 2015;20(1):57-63.
12. Lima MCMP, Rossi TRF, Françozo MFC, CollelaSantos MF, Correa CR. Analysis of neonatal hearing screening program performed on an outpatient basis: analysis of an outpatient hearing screening program. Int J Pediatr Otorhinolaryngol. 2015;79(12):2227-33.

13. Sabbag JC, Lacerda ABM. Neonatal hearing screening in primary health care and family health care. CoDAS. 2017;29(4):1-7.

14. Januário GC, Lemos $S M A$, de Lima Friche $A A$, Alves CR. Quality indicators in a newborn hearing screening service. Braz J Otorhinolaryngol. 2015;81(3):255-63.

15. Pinto JD, Ferreira L, Temp DA, Dias V, Rohers DE, Biaggio EPV. Evasion of newborn hearing screening retest: relation with risk factors for hearing impairment. Rev. CEFAC. 2019;21(4):1-7.

16. Cruz LRL, Ferrite S. Cobertura estimada da triagem auditiva neonatal para usuários do Sistema Único de Saúde, Brasil, 2008-2011. Rev Bras Saúde Mater Infant. 2014;14(4):401-11.

17. Cavalcanti HG, de Melo LP, Buarque LF, Guerra RO. Overview of newborn hearing screening programs in Brazilian maternity hospitals. Braz $\mathrm{J}$ Otorhinolaryngol. 2014;80(4):346-53.

18. Lammers MJW, Jansen TTG, Grolman W, Lenarz $\mathrm{T}$, Versnel $\mathrm{H}$, van Zanten $\mathrm{GA}$ et al. The influence of Newborn Hearing Screening on the age at cochlear implantation in children. Laryngoscope. 2015;125(4):985-90.

19. Lachowska M, Surowiec P, Morawski K, Pierchala K, Niemczyk K. Second stage of Universal Neonatal Hearing Screening - a way for diagnosis and beginning of proper treatment for infants with hearing loss. Adv Med Sci-Poland. 2015;59(1):90-4.

20. Kemaloglu YK, Gokdogan Ç, Gunduz B, Onal EE, Turkyilmaz C, Atalay Y. Newborn hearing screening outcomes during the first decade of the program in a reference hospital from Turkey. Eur Arch Otorhinolaryngol. 2016;273(5):1143-9.

21. Bongiolo MR, Silva ACB, Cancelier AC, Bongiolo MR, Souza MEV, Nitz VO. Avaliação dos resultados das emissões otoacústicas em hospital do sul de Santa Catarina. Rev AMRIGS. 2015;59(4):1-5.

22. Ravi R, Gunjawate DR, Yerraguntla K, Lewis LE, Driscoll C, Rajashekhar B. Follow-up in newborn hearing screening - a systematic review. Int $\mathrm{J}$ Pediatrotorhinolaryngol. 2016;90:29-36. 
23. Hunter LL, Meinzen-Derr J, Wiley S, Horvath CL, Kothari R, Wexelblatt $S$. Influence of the WIC Program on loss to follow-up for newborn hearing screening. Pediatrics. 2016;138(1):1-8.

24. Dimitriou A, Perisanidis C, Chalkiadakis V, Marangoudakis $P$, Tzagkaroulakis A, Nikolopoulos TP. The universal newborn hearing screening program in a public hospital: the importance of the day of examination. Int $\mathrm{J}$ Pediatrotorhinolaryngol. 2016;91:90-3.

25. Tonon T, Sisti E, Nalin T, Schwartz IVD. Assessment of newborn screening in the public health system of a municipality in northern Rio Grande do Sul. Clin Biomed Res. 2018;38(2):123-7.

26. Alam S, Gaffney M, Eichwald J. Improved newborn hearing screening follow-up results in more infants identified. J Public Health ManagPract. 2014;20(2):220-3.

27. D'innocenzo M, Adami NP, Cunha ICKO. O movimento pela qualidade nos serviços de saúde e enfermagem. Rev Bras Enferm. 2006;59(1):84-8.

28. Us Preventive Services Task Force. Universal screening for hearing loss in newborns: US Preventive Services Task Force recommendation statement. Pediatrics. 2008;122(1):143-8. 